\title{
MicroRNA-9 enhances sensitivity to cetuximab in epithelial phenotype hepatocellular carcinoma cells through regulation of the eukaryotic translation initiation factor $5 \mathrm{~A}-2$
}

\author{
FEI XUE ${ }^{1}$, YUNTIAN LIANG ${ }^{1}$, ZHENRONG LI ${ }^{1}$, YANHUI LIU ${ }^{2}$, HONGWEI ZHANG ${ }^{1}$, \\ YU WEN $^{1}$, LEI YAN ${ }^{1}$, QIANG TANG ${ }^{1}$, ERHUI XIAO ${ }^{1}$ and DONGYI ZHANG ${ }^{1}$ \\ Departments of ${ }^{1}$ Hepatobiliary and Pancreatic Surgery, and ${ }^{2}$ Hematology, Henan Provincial People's Hospital, \\ Zhengzhou University People's Hospital, Henan University People's Hospital, Zhengzhou, Henan 410003, P.R. China
}

Received October 8, 2016; Accepted September 22, 2017

DOI: 10.3892/ol.2017.7399

\begin{abstract}
Hepatocellular carcinoma (HCC) is one of the most widespread malignant human tumors worldwide. Treatment options include radiotherapy, surgical intervention and chemotherapy; however, drug resistance is an ongoing treatment concern. In the present study, the effects of a microRNA (miR/miRNA), miR-9, on the sensitivity of HCC cell lines to the epidermal growth factor receptor inhibitor, cetuximab, were examined. miR-9 has been proposed to serve a role in tumorigenesis and tumor progression. In the present study, bioinformatics analyses identified the eukaryotic translation initiation factor 5A2 (eIF-5A-2) as a target of miR-9. The expression levels of miR-9 and eIF-5A-2 were examined by reverse transcription-quantitative polymerase chain reaction and HCC cell lines were transfected with miR-9 mimics and inhibitors to determine the effects of the miRNA on cell proliferation and viability. The miR-9 mimic was revealed to significantly increase the sensitivity of epithelial phenotype HCC cells (Hep3B and Huh7) to cetuximab, while the miR-9 inhibitor triggered the opposite effect. There were no significant differences in sensitivity to cetuximab observed in mesenchymal phenotype HCC cells (SNU387 and SNU449). Cells lines displaying high expression levels of eIF-5A-2 were more resistant to cetuximab. Transfection of cells with a miR-9 mimic resulted in downregulation of the expression of eIF-5A-2 mRNA, while an miR-9 inhibitor increased expression. When expression of eIF-5A-2 was knocked down with siRNA, the effects of miR-9 on cetuximab sensitivity were no longer observed. Taken together, these data support a role
\end{abstract}

Correspondence to: Dr Fei Xue, Department of Hepatobiliary and Pancreatic Surgery, Henan Provincial People's Hospital, Zhengzhou University People's Hospital, Henan University People's Hospital, 7 Weiwu Road, Zhengzhou, Henan 410003, P.R. China

E-mail: xuefeidoctor@163.com

Key words: hepatocellular carcinoma, microRNA-9, cetuximab, eukaryotic translation initiation factor 5A-2, drug resistance for miR-9 in enhancing the sensitivity of epithelial phenotype HCC cells to cetuximab through regulation of eIF-5A-2.

\section{Introduction}

Hepatocellular carcinoma (HCC) is one of the most common primary malignancies of the liver, the third leading cause of cancer-associated mortalities after stomach and lung cancer, and the sixth most common neoplasm worldwide $(1,2)$. Current treatments for HCC include chemotherapy, radiotherapy and surgical intervention. However, drug resistance is a growing concern as a result of the increased application of chemotherapeutics (3). Determining the molecular mechanisms underlying drug resistance in HCC cells is therefore imperative.

MicroRNAs (miRNAs/miRs) are small, non-coding RNAs that modulate post-transcriptional gene expression by binding to the 3'-untranslated region (3'-UTR) of target mRNAs, in addition to being involved in the regulation of essential cellular processes, including proliferation, diversification, metastasis and apoptosis, particularly in cancer development and progression (4-6). Aberrant miRNA expression has demonstrated potential as a prognostic or diagnostic marker in various types of cancer, including breast, non-small cell lung and colon cancer (7-10). The expression levels of miRNAs reflect the developmental lineage and differentiation state of tumors (11). Studies have demonstrated that miR-185 suppresses cell growth and epithelial-mesenchymal transition progression by targeting Six 2, providing a novel target for the molecular treatment of liver malignancies (12). It has been demonstrated that a loss of miR-211 expression, and consequently uncontrolled secreted protein, acidic and rich in cysteine overexpression, may drive progression of HCC (13).

Previous studies have indicated that the levels of miR-9 are downregulated in certain types of cancer, such as ovarian cancer, gastric cancer and neuroblastoma (14-17); however, it has also been revealed that the expression of miR-9 is upregulated in colorectal, breast, lung and laryngeal squamous cell cancer types (18-22). Other studies have indicated that miR-9 may serve a major role in tumor progression and tumorigenesis (23). The eukaryotic translation initiation factor 
$5 \mathrm{~A}-2$ (eIF-5A-2), located at $3 \mathrm{q} 26$, is one of the most frequently observed chromosomal alterations in ovarian carcinoma (24). Overexpression of eIF-5A-2 has also been observed in other solid tumors and has been defined as an adverse prognostic marker in HCC (25), ovarian carcinoma (26), bladder carcinoma (27) and non-small cell lung cancer (28), and as a metastasis-promoting factor in HCC (29) and colorectal carcinoma (30). In the present study, an miRNA target prediction website, TargetScan (www.targetscan.org), was used to identify potential targets of miR-9. The 3'UTR of eIF-5A-2 was identified as a potential target, and examination of the sequence of the 3'UTR of eIF-5A-2 identified multiple potential sites for interaction with miR-9. The mechanisms underlying the role of miR-9 in the regulation of HCC cells have not been characterized. We hypothesized that miR-9 may affect the expression of eIF-5A-2 and, furthermore, may regulate the sensitivity of epithelial HCC cells to cetuximab.

The present study investigated the effects of miR-9/eIF-5A-2-regulated cetuximab sensitivity in HCC cell lines and monitored the expression of miR-9 and eIF-5A-2 mRNA. We aimed to investigate whether or not miR-9, through regulating the expression of eIF-5A-2, may affect the sensitivity of $\mathrm{HCC}$ cells with an epithelial phenotype to cetuximab.

\section{Materials and methods}

Cell culture. Human HCC cell lines (Hep3B, Huh7, SNU387 and SNU449) were obtained from American Type Culture Collection (ATCC; Manassas, VA, USA). Huh7 cells (epithelial phenotype HCC) were maintained in Dulbecco's modified Eagle's medium containing $10 \%$ fetal bovine serum (FBS; Gibco; Thermo Fisher Scientific, Inc., Waltham, MA, USA) and $1 \%$ penicillin/streptomycin (Sigma-Aldrich; Merck KGaA, Darmstadt, Germany). SNU387 and SNU449 cells (mesenchymal phenotype HCC) were cultured in RPMI-1640 medium (Gibco; Thermo Fisher Scientific, Inc.) supplemented with $10 \% \mathrm{FBS}$ and $1 \%$ penicillin/streptomycin. Hep3B cells (epithelial phenotype HCC) were cultured in minimum essential medium (MEM; Gibco; ThermoFisher Scientific,Inc.) supplemented with $10 \% \mathrm{FBS}$ and $1 \%$ penicillin/streptomycin. All cells were maintained under $5 \% \quad \mathrm{CO}_{2}$ at $37^{\circ} \mathrm{C}$ in a humidified incubator. Cetuximab and the miR-9 mimic and inhibitor were all purchased from Guangzhou RiboBio Co., Ltd. (Guangzhou, China). The eIF-5A-2 siRNA and negative control siRNA were designed by and purchased from Santa Cruz Biotechnology, Inc. (Dallas, TX, USA). Furthermore, TargetScan (www.targetscan.org) was to predict the associated miRNAs for eIF-5A-2. Briefly, we opened TargetScan was opened and the human species chosen. The gene symbol eIF-5A-2 was searched to obtain the predicted associated miRNAs.

siRNA transfections. HCC cell lines were transfected with eIF-5A-2 siRNA (100 nM; Santa Cruz Biotechnology, Inc.; forward, 5'-TATGCAGTGCTCGGCCTTG-3' and reverse, 5'-TTGGAACATCCATGTTGTGAGTAGA-3') or a negative control siRNA using Lipofectamine 2000 (Thermo Fisher Scientific, Inc.) according to the manufacturer's protocols. The transfection medium (Opti-MEM; Gibco; Thermo Fisher
Scientific, Inc.) was replaced with complete medium (Gibco; Thermo Fisher Scientific, Inc.) $6 \mathrm{~h}$ after transfection, and the cells were incubated at $37^{\circ} \mathrm{C}$ for $24 \mathrm{~h}$. All treatments were initiated $24 \mathrm{~h}$ after transfection.

Cell viability assay. HCC cell lines or siRNA-transfected HCC cell lines were seeded onto 96-well plates at a density of $5 \times 10^{3}$ cells/well. The medium was replaced with the corresponding serum-free medium for $24 \mathrm{~h}$ to synchronize the cells, prior to the culture medium being replaced with complete medium containing the drug at the indicated concentrations (Cetuximab: Hep3B, 2,229 $\mu \mathrm{g} / \mathrm{ml}$; Huh7, 2,564 $\mu \mathrm{g} / \mathrm{ml}$; SNU387, 3,182 $\mu \mathrm{g} / \mathrm{ml}$; SNU449, 2,450 $\mu \mathrm{g} / \mathrm{ml}$ ) for $48 \mathrm{~h}$ at $37^{\circ} \mathrm{C}$. Following treatment, $10 \mu \mathrm{l}$ Cell Counting kit- 8 solution was added and the cells were incubated at $37^{\circ} \mathrm{C}$ for a further $3 \mathrm{~h}$. Subsequently, absorbance at $450 \mathrm{~nm}$ was measured using an MRX II microplate reader (Dynex Technologies, Inc., Chantilly, VA, USA). Relative cell viability was calculated as a percentage of the untreated controls.

Western blot analysis. To extract proteins after $48 \mathrm{~h}$ of treatment, cell lysis buffer (Cell Signaling Technology, Inc., Danvers, MA, USA) containing protease inhibitors (Sigma-Aldrich; Merck KGaA) was added to harvested HCC cells in an ice bath. Cells were centrifuged at 12,000 x g for $5 \mathrm{~min}$ at $4^{\circ} \mathrm{C}$ following the lysis. The supernatant was collected and the protein concentration was measured with a bicinchoninic acid protein assay kit (Sigma-Aldrich; Merck $\mathrm{KGaA})$. The protein samples (40 $\mu \mathrm{g} /$ lane) were separated by $10 \%$ SDS-PAGE and transferred to polyvinylidene difluoride membranes (EMD Millipore, Billerica, MA, USA). Membranes were blocked with Tris-buffered saline and $0.1 \%$ Tween 20 (TBST) containing 5\% bovine serum albumin at $37^{\circ} \mathrm{C}$ for $2 \mathrm{~h}$, and incubated overnight at $4^{\circ} \mathrm{C}$ with the eIF-5A-2 primary antibody (Abcam, Cambridge, MA, USA; ab150439; diluted 1:1,000 in TBST). The membranes were washed 3 times with TBST and were incubated with a horseradish peroxidase-conjugated secondary antibody (Abcam; ab97051; 1:2,000) for $2 \mathrm{~h}$ at room temperature. The protein bands were detected using an enhanced chemiluminescence kit (GE Healthcare Life Sciences, Little Chalfont, UK). Bands were quantified by densitometry using Image Lab version 5.0 (Bio-Rad Laboratories, Inc., Hercules, CA, USA) and GAPDH (Cell Signaling Technology, Inc.; cat no. 5174S; diluted 1:2,000 in TBST) was used as an internal control.

5-ethynyl-2'-deoxyuridine (EdU) incorporation assay. HCC cell lines were seeded onto 96 -well plates at a density of $5 \times 10^{3}$ cells/well in their respective growth medium. The medium was replaced with the corresponding serum-free medium to synchronize the cells. After $24 \mathrm{~h}$, the serum-free medium was replaced with growth medium containing drugs at the aforementioned concentrations (Cetuximab: Hep3B, 2,229 $\mu \mathrm{g} / \mathrm{ml}$; Huh7, 2,564 $\mu \mathrm{g} / \mathrm{ml}$; SNU387, 3,182 $\mu \mathrm{g} / \mathrm{ml}$; SNU449, 2,450 $\mu \mathrm{g} / \mathrm{ml}$ ) for $48 \mathrm{~h}$. Cell proliferation was assessed through an EdU assay using the Click-iTEdU Imaging kit (Invitrogen; Thermo Fisher Scientific, Inc., Waltham, MA, USA) according to the manufacturer's protocols, and cells were counterstained with $100 \mu$ l Hoechst 3342 at room temperature for $30 \mathrm{~min}$ in the dark. 
Reverse transcription-quantitative polymerase chain reaction $(R T-q P C R)$. Total RNA was extracted from Hep3B, Huh7, SNU387 and SUN449 cells using TRIzol reagent (Invitrogen; Carlsbad, CA, USA) and reverse transcribed into cDNA using Prime Script reagent RT kit (Takara Biotechnology, Co., Ltd., Dalian, China) and the following thermocycling conditions: $42^{\circ} \mathrm{C}$ for $2 \mathrm{~min}, 15 \mathrm{~min}$ at $37^{\circ} \mathrm{C}$ and $5 \mathrm{sec}$ at $85^{\circ} \mathrm{C}$. Expression of eIF-5A-2 mRNA was normalized to $\mathrm{U} 6$ and relative quantification was performed using the comparative $2^{-\Delta \Delta \mathrm{Ct}}$ method (31). SYBR Green PCR (Takara Biotechnology, Co., Ltd., Dalian, China) was performed at $95^{\circ} \mathrm{C}$ for $30 \mathrm{sec}$, followed by 40 cycles of denaturation at $95^{\circ} \mathrm{C}$ for $5 \mathrm{sec}$ and annealing at $60^{\circ} \mathrm{C}$ for $30 \mathrm{sec}$. All reactions were performed in triplicate. The primers were as follows: eIF-5A-2 forward, 5'-TATGCAGTGCTC GGCCTTG-3', and reverse, 5'-TTGGAACATCCATGTTGT GAGTAGA-3'; and miR-9, 5'-TCTTTGGTTATCTAGCTG TATGA-3'. Negative control: Sense, 5'-UUCUCCGAACGU GUCACGUTT-3' and antisense, 5'-ACGUGACACGUUCGG AGAATT-3'.

Statistical analysis. Data are presented as the mean \pm standard deviation. Statistical analysis was performed using GraphPad Prism 5 software (GraphPad Software, Inc., La Jolla, CA, USA). Comparisons between 2 independent groups were performed using Student's t-test $\mathrm{P}<0.05$ was considered to indicate a statistically significant difference.

\section{Results}

miR-9 regulates the sensitivity of HCC cells with an epithelial phenotype to cetuximab. To assess whether miR-9 acted in a synergistic or antagonistic manner with cetuximab, HCC cell lines were treated with cetuximab alone, or cetuximab with an miR-9 mimic or inhibitor for 48 h. A CCK-8 assay was then used to assess the cytotoxicity of cetuximab. As demonstrated in Fig. 1A and B, compared with cetuximab treatment alone, the addition of a miR-9 mimic significantly increased the sensitivity to cetuximab, while the addition of a miR-9 inhibitor significantly decreased the sensitivity of epithelial phenotype HCC cells (Hep3B and Huh7). In the mesenchymal phenotype HCC SNU387 and SNU449 cells, no significant differences were observed among the groups (Fig. 1C and D). EdU incorporation assays were also performed to determine the effects on proliferation of each treatment condition. The results revealed that the proliferation of HCC cells (Fig. 1E and F) was significantly reduced following treatment with cetuximab plus the miR-9 mimic and significantly increased following treatment with cetuximab plus the miR-9 inhibitor in the Hep3B and Huh7 cells. No significant differences were observed between the 2 groups in the mesenchymal phenotype HCC cells (Fig. 1G and H). Taken together, these results demonstrate that miR-9 may enhance the sensitivity of epithelial phenotype HCC cells to cetuximab.

miR -9 regulates the expression of eIF-5A-2. Bioinformatics analysis using Targetscan software suggested that eIF-5A-2 was a target gene of miR-9 (Fig. 2A). RT-qPCR was used to determine the miR-9 and eIF-5A-2 mRNA expression in
HCC cell lines (Fig. 2B). Mesenchymal phenotype SNU387 and SNU449 cell lines were revealed to exhibit higher miR-9 expression than the epithelial phenotype Hep3B and Huh7 cell lines. The expression of eIF-5A-2 was negatively associated with the expression of miR-9 in the HCC cells. RT-qPCR was then performed to evaluate the effects of miR-9 on the expression of eIF-5A-2 mRNA. eIF-5A-2 mRNA expression was markedly decreased when HCC cells were transfected with the miR-9 mimic, compared with that in cells transfected with the negative control mimic. By contrast, transfection with an miR-9 inhibitor enhanced the expression of eIF-5A-2 mRNA (Fig. 2C). RT-qPCR was used to determine the expression of miR-9 following treatment with an miR-9 mimic or inhibitor, the results demonstrated that miR-9 expression was increased after transfection with miR-9 mimic and was decreased after transfected with miR-9 inhibitor compared with the control (Fig. 2D). Western blot analysis demonstrated downregulation of eIF-5A-2 in miR-9 mimic-transfected HCC cells and upregulation of eIF-5A-2 in miR-9 inhibitor-transfected HCC cells (Fig. 2E).

Knockdown of eIF-5A-2 enhances cetuximab sensitivity in epithelial phenotype HCC cells. To determine whether altered expression of eIF-5A-2 may affect the sensitivity of HCC cells to cetuximab, eIF-5A-2 siRNA or a negative control siRNA were transfected into the HCC cell lines. Western blot analysis was used to examine the knockdown efficiency (Fig. 3A). A CCK-8 assay was then used to measure cell viability following treatment with cetuximab. It was revealed that knockdown of eIF-5A-2 significantly improved cetuximab-induced growth inhibition in epithelial HCC cells (Fig. 3B and C), but had no significant effect on mesenchymal HCC cells (Fig. 3D and E). These data suggest that eIF-5A-2 is involved in the sensitivity of epithelial HCC cells to cetuximab.

miR-9 regulates the sensitivity of epithelial phenotype $H C C$ cells to cetuximab through eIF-5A-2. In order to determine whether or not miR-9 enhanced the sensitivity of epithelial $\mathrm{HCC}$ cells to cetuximab through regulation of eIF-5A-2, HCC cells were transfected with eIF-5A-2 siRNA and the viability of HCC cell lines treated with cetuximab alone, with cetuximab plus a miR-9 mimic or with cetuximab plus a miR-9 inhibitor, for $48 \mathrm{~h}$ was measured. The results demonstrated that silencing of eIF-5A-2 resulted in no significant differences in the viability of cells treated with cetuximab with or without a miR-9 mimic or an inhibitor (Fig. 4A-D). Therefore, we hypothesized that miR-9 increased the sensitivity of these cells to cetuximab through the regulation of eIF-5A-2.

\section{Discussion}

miRNAs are a family of small interfering RNAs that modulate gene expression in a sequence-specific manner (32). miRNAs have been revealed to serve critical roles in cell growth, differentiation, apoptosis and drug resistance (32). Several studies have demonstrated that upregulation of miR-9 expression is associated with enhanced tumor cell invasion and a poor prognosis $(33,34)$. These studies support a role for miR-9 as an oncogene in these tumor types. Notably, miR-9 has also 

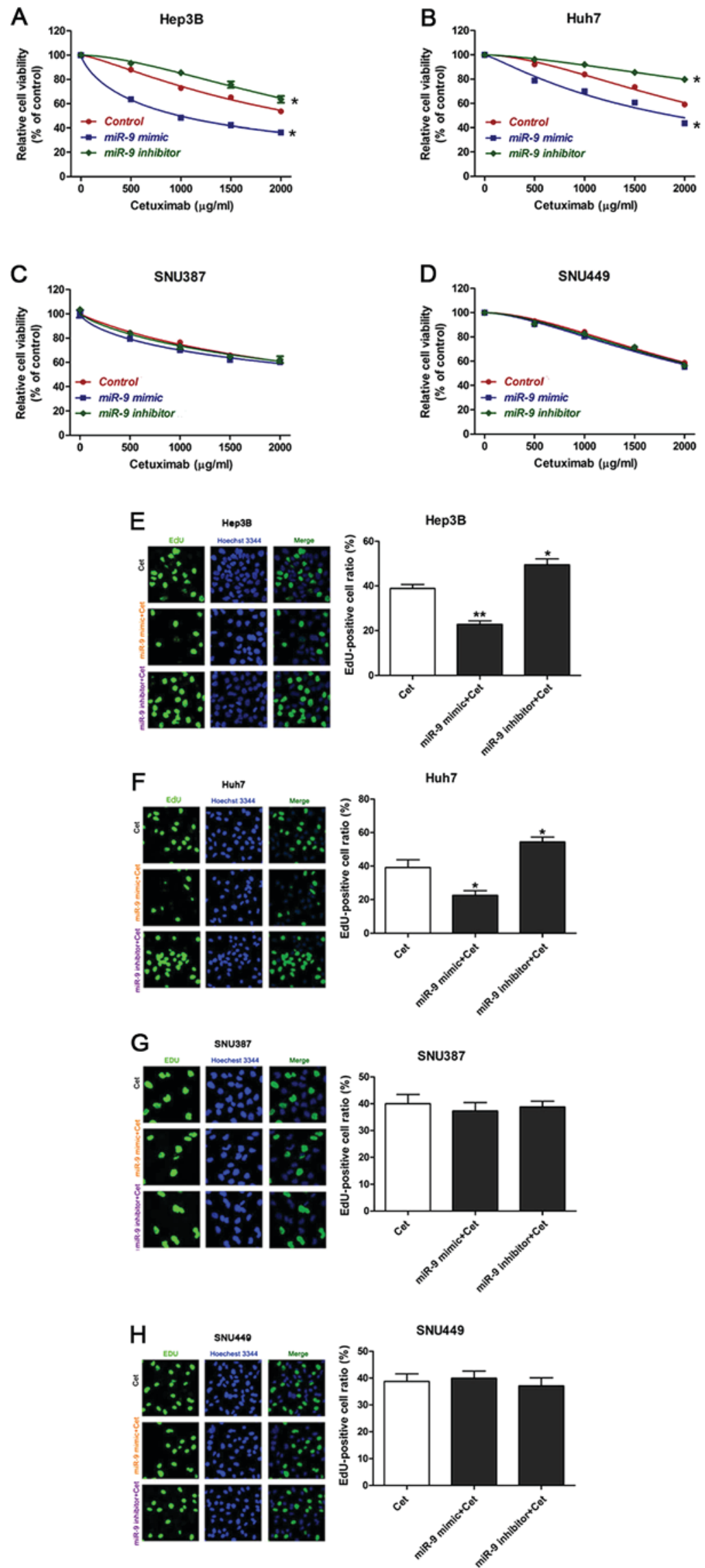

Figure 1. Overexpression of miR-9 enhances sensitivity of epithelial HCC cells to cetuximab. (A-D) Viability of HCC cells treated with cetuximab in the presence of a miR-9 mimic or inhibitor. (E-H) Photomicrographs and bar charts depicting EdU staining and relative EdU-positive ratios, respectively, of HCC cells following treatment with cetuximab, with cetuximab plus a miR-9 mimic or with cetuximab plus miR-9 inhibitor for 48 h. " $\mathrm{P}<0.05$, ${ }^{* *} \mathrm{P}<0.01 \mathrm{vs}$. control,

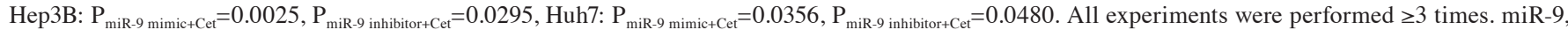
microRNA-9; HCC, hepatocellular carcinoma; EdU, 5-ethynyl-2'-deoxyuridine; Cet, cetuximab. 
A Human EIF5A2 ENST00000295822.2 3' UTR length: 4945

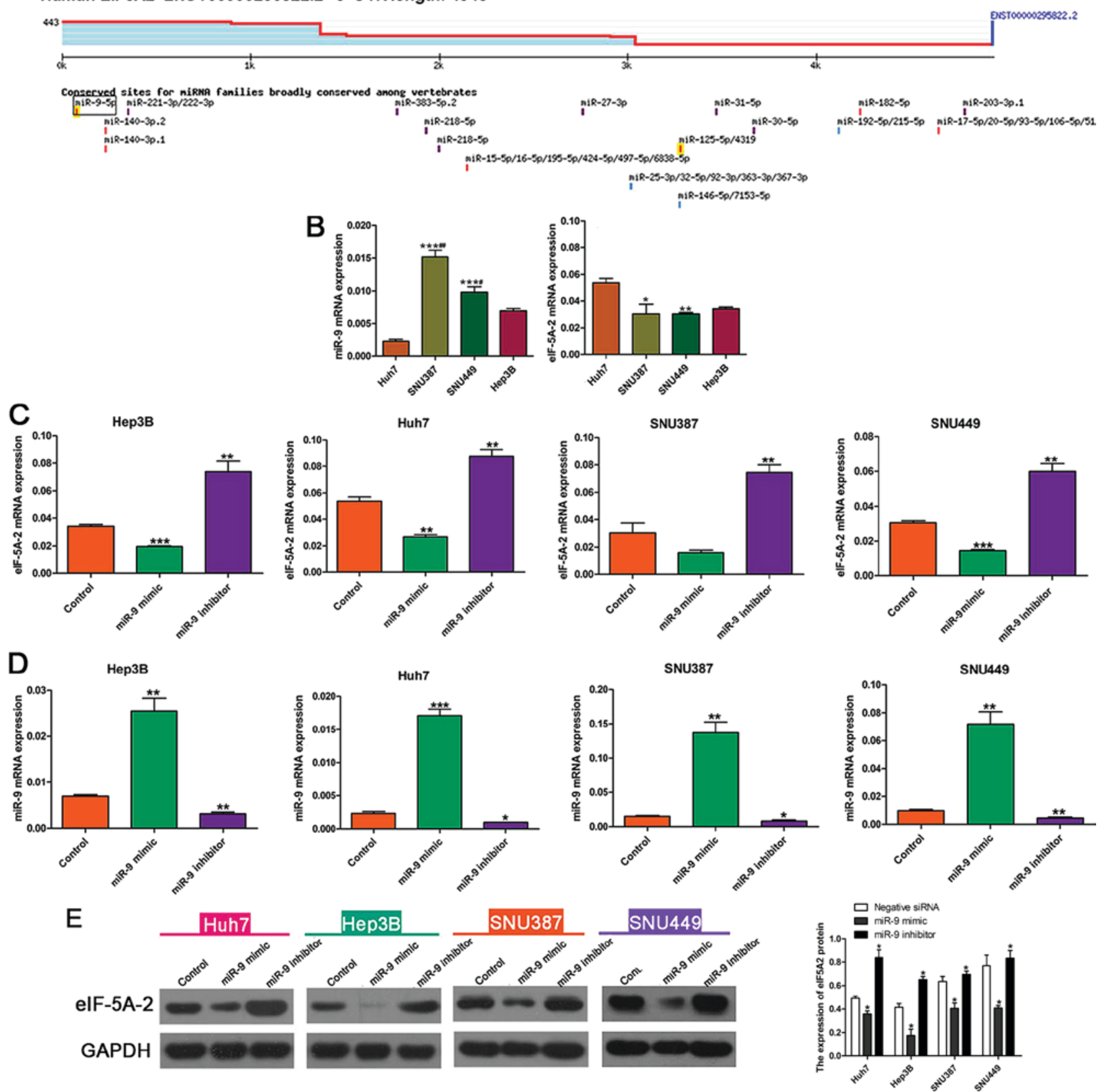

Figure 2. miR-9 modulates expression of eIF-5A-2 in HCC cell lines. (A) miR-9 target site in eIF-5A-2 predicted by TargetScan. (B) Expression of miR-9 and eIF-5A-2 mRNA in HCC cells as determined by RT-qPCR. ${ }^{*} \mathrm{P}<0.05,{ }^{* *} \mathrm{P}<0.01,{ }^{* * *} \mathrm{P}<0.001$ vs. Huh7; ${ }^{*} \mathrm{P}<0.05$, ${ }^{\# \#} \mathrm{P}<0.01$ vs. Hep3B. (C) eIF-5A-2 expression in HCC cells following treatment with a miR-9 mimic or inhibitor as determined by RT-qPCR. ${ }^{* *} \mathrm{P}<0.01,{ }^{* * * *} \mathrm{P}<0.001$ vs. the control. (D) Expression levels of miR-9 following treatment with a miR-9 mimic or inhibitor as determined by RT-qPCR. ${ }^{*} \mathrm{P}<0.05,{ }^{* * *} \mathrm{P}<0.01,{ }^{* * * *} \mathrm{P}<0.001$ vs. the control (E) Western blot analysis was used to detect eIF-5A-2 expression in the various HCC cell lines in the presence of the miR-9 mimic, inhibitor and control. "P<0.05 vs. negative siRNA. miR-9, microRNA-9; eIF-5A-2; eukaryotic translation initiation factor 5A-2; HCC, hepatocellular carcinoma; RT-qPCR, reverse transcription-quantitative polymerase chain reaction; miRNA, microRNA; UTR, untranslated region.

been reported as a tumor suppressor in various human cancer types. These studies have demonstrated that miR-9 may inhibit cancer cell proliferation. Taken together, these data indicate that miR-9 may act either as an oncogene or as a tumor suppressor. In the present study, the effects of miR-9 on HCC cells were examined and miR-9 overexpression was revealed to inhibit HCC cell proliferation. A CCK-8 assay was used to determine the effect of miR-9 on cell viability following treatment with cetuximab. An miR-9 mimic significantly increased the sensitivity of epithelial phenotype HCC cells to cetuximab, while an miR-9 inhibitor significantly decreased cetuximab sensitivity in these cells.

eIF-5A-2 serves important roles in cell proliferation, metastasis and apoptosis, and is considered as a novel oncogene (28). Accumulating evidence has demonstrated upregulated expression of eIF-5A-2 in a number of cancer types, such as bladder cancer, hepatocellular carcinoma and colon cancer (35-37). Inhibition of eIF-5A-2 may decrease invasion and metastasis, and enhance the therapeutic efficacy of drugs in HCC cells $(38,39)$. Cetuximab, an anti-epidermal growth 
A
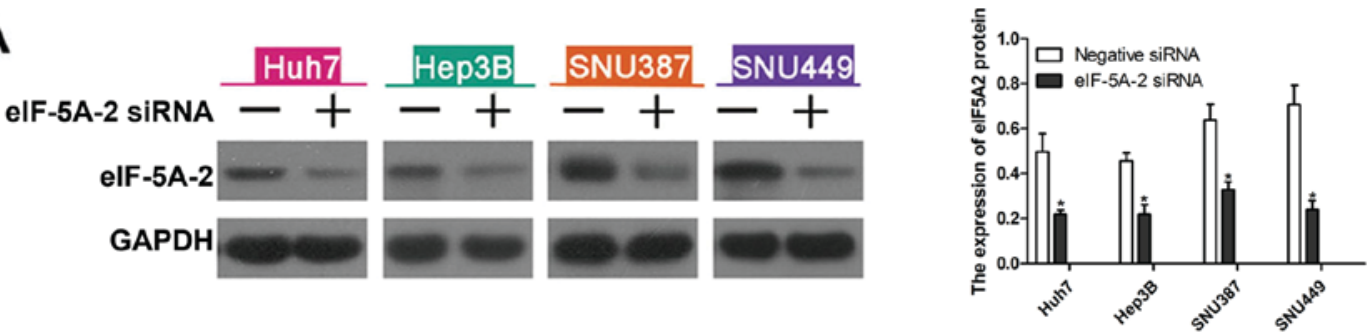

B

Hep3B

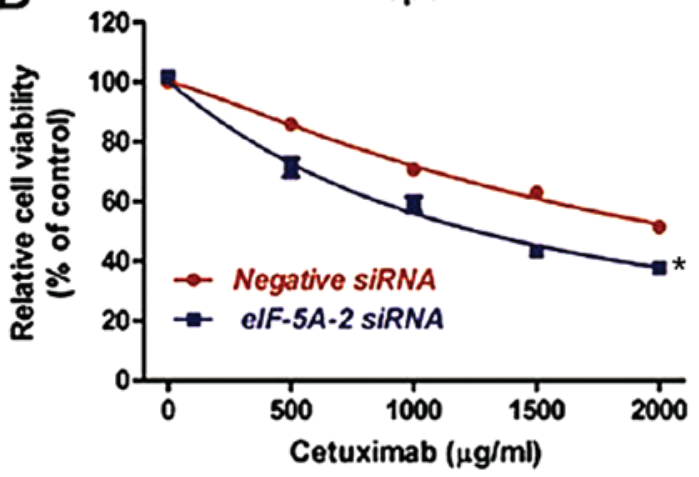

C

Huh7

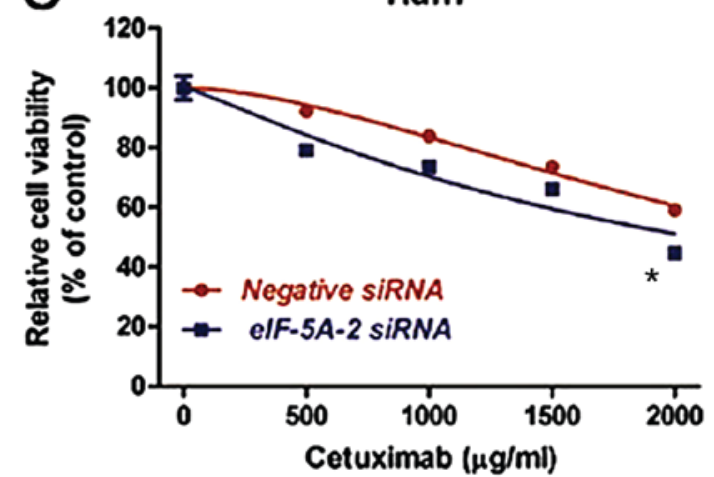

D

SNU387

E

SNU449
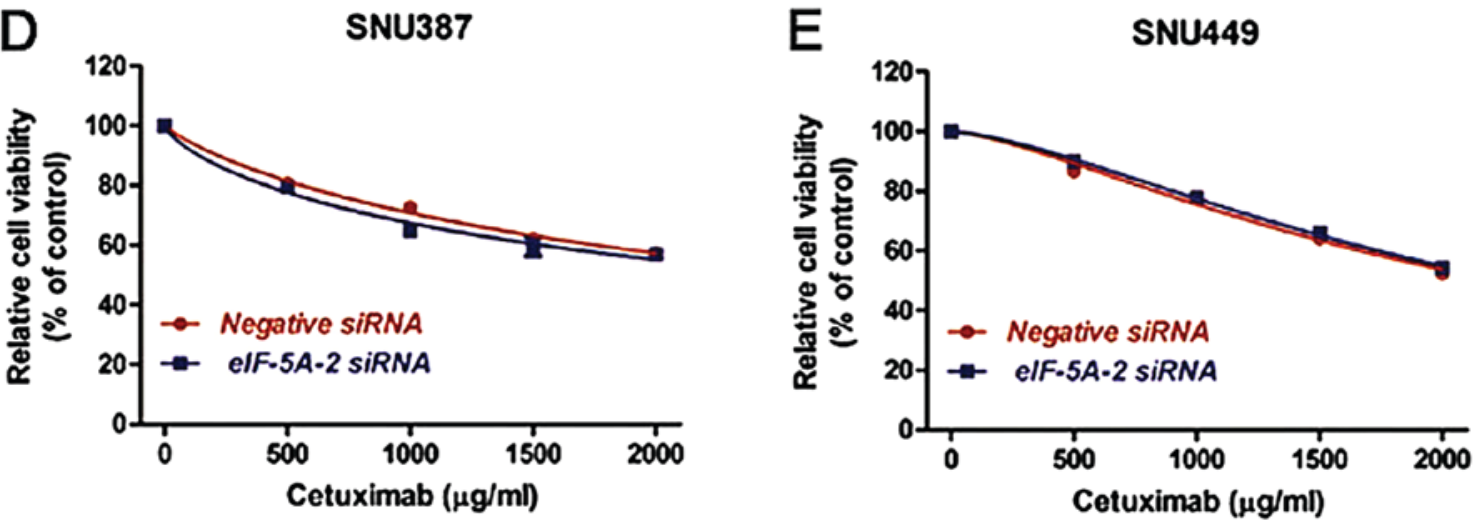

Figure 3. Sensitivity of HCC cell lines to cetuximab. (A) Western blot analysis of eIF-5A-2 expression in eIF-5A-2 siRNA-transfected cells. GAPDH served as a loading control. Knockdown of eIF-5A-2 enhanced the sensitivity of the epithelial phenotype HCC cells, (B) Hep3B and (C) Huh7, to cetuximab, but had no significant effect on the mesenchymal phenotype HCC cells, (D) SNU387 and (E) SNU449. "P<0.05 vs. negative siRNA. HCC, hepatocellular carcinoma; eIF-5A-2; eukaryotic translation initiation factor 5A-2; siRNA, small interfering RNA.
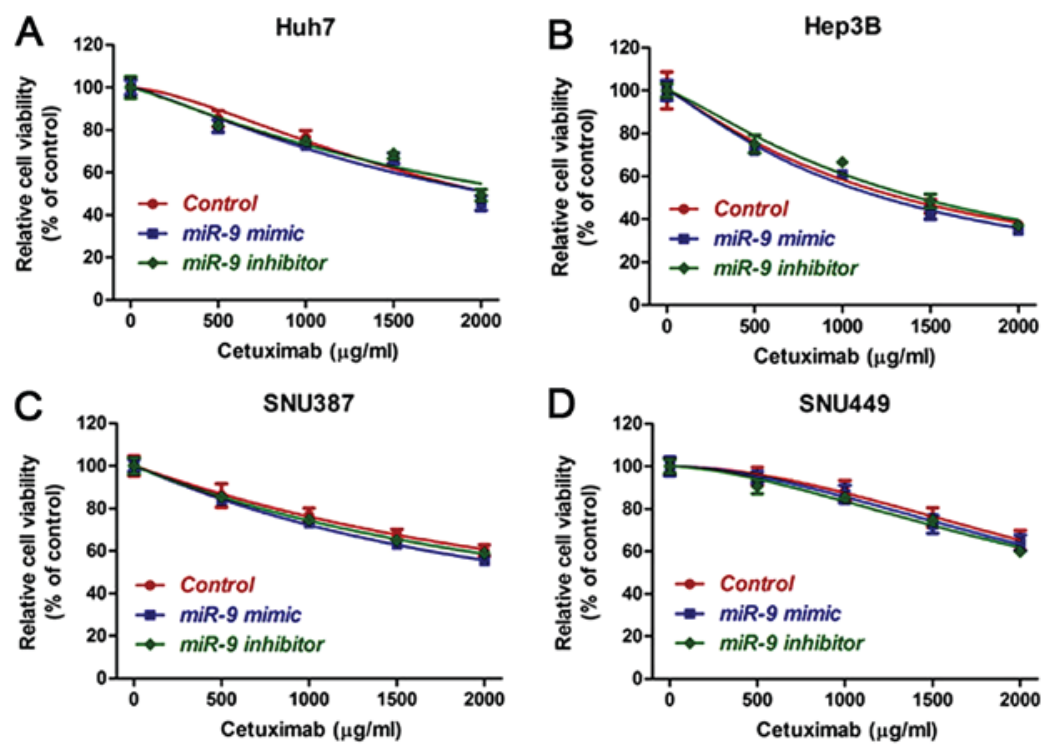

Figure 4. Cytotoxicity of cetuximab or cetuximab plus an miR-9 mimic or inhibitor in hepatocellular carcinoma cell lines, (A) Huh7, (B) Hep3B, (C) SNU387 and (D) SNU449, treated with eIF-5A-2 siRNA. miR-9, microRNA-9. 
factor receptor (EGFR) monoclonal antibody that targets the extracellular domain of EGFR, is used to treat several cancer types (40); for example, it is used for the treatment of patients with colorectal cancer and squamous cell carcinoma of the head and neck $(41,42)$. It has been demonstrated that combination treatment with the eIF-5A-2 inhibitor, GC7, enhances cetuximab sensitivity by inhibiting eIF-5A-2 in non-small cell lung cancer (43). Studies identified activated EGFR as a potential determinant that promoted the resistance of HCC cells to sorafenib, while inhibition of EGFR with cetuximab increased the efficacy of sorafenib (44). Furthermore, a novel signal transducer and activator of transcription 3 inhibitor, NSC 74859, enhanced the anti-proliferative activity of cetuximab in HCC (45). However, single use of cetuximab was only slightly effective in clinical trials and drug resistance may be an issue. It is therefore imperative to increase the cytotoxicity of cetuximab in the treatment of HCC. In the present study, Huh7 cells were the most resistant to cetuximab among all the HCC cell lines. Notably, the eIF-5A-2 mRNA expression in the Huh7 cells was higher than that in the other HCC cell lines. The siRNA-mediated silencing of eIF-5A-2 resulted in enhanced sensitivity of the HCC cells to cetuximab. We also confirmed that inhibition of eIF-5A-2 could enhance the cytotoxicity of cetuximab in HCC. These discoveries indicate that eIF-5A-2 may be involved in cetuximab resistance in HCC cell lines. In the present study, miR-9 overexpression was revealed to downregulate the expression of eIF-5A-2 mRNA, while an miR-9 inhibitor increased eIF-5A-2 mRNA expression. These findings indicate that miR-9 may regulate the expression of eIF-5A-2. Additionally, the effects of miR-9 on cetuximab sensitivity were revealed to be eliminated by knockdown of eIF-5A-2 with siRNA.

In summary, the present study demonstrated that overexpression of miR-9 downregulated the expression of eIF-5A-2 and enhanced the sensitivity of epithelial phenotype HCC cells to cetuximab. Taken together, these results indicate that the use of miR-9 may serve as a potential therapeutic approach for $\mathrm{HCC}$ in the future.

\section{Acknowledgements}

This study was supported by the National Natural Science Foundation of China (grant no. 81273260), the Natural Science Foundation of Henan Province (grant no. 162300410274) and Zhejiang Provincial Natural Science Foundation of China (grant no. LQ13H160006).

\section{References}

1. Faloppi L, Scartozzi M, Maccaroni E, Di Pietro Paolo M, Berardi R, Del Prete M and Cascinu S: Evolving strategies for the treatment of hepatocellular carcinoma: From clinical-guided to molecularly-tailored therapeutic options. Cancer Treat Rev 37: 169-177, 2011.

2. Sapisochin G, de Sevilla EF, Echeverri J and Charco R: Management of 'very early' hepatocellular carcinoma on cirrhotic patients. World J Hepatol 6: 766-775, 2014.

3. Thomas RK: Overcoming drug resistance in ALK-rearranged lung cancer. N Engl J Med 370: 1250-1251, 2014.

4. Selcuklu SD, Donoghue MT, Rehmet K, de Souza Gomes M, Fort A, Kovvuru P, Muniyappa MK, Kerin MJ, Enright AJ and Spillane C: MicroRNA-9 inhibition of cell proliferation and identification of novel miR-9 targets by transcriptome profiling in breast cancer cells. J Biol Chem 287: 29516-29528, 2012.
5. Song Y, Li J, Zhu Y, Dai Y, Zeng T, Liu L, Li J, Wang H, Qin Y, Zeng M, et al: MicroRNA-9 promotes tumor metastasis via repressing E-cadherin in esophageal squamous cell carcinoma. Oncotarget 5: 11669-11680, 2014.

6. Calin GA and Croce CM: MicroRNA signatures in human cancers. Nat Rev Cancer 6: 857-866, 2006.

7. Cui EH, Li HJ, Hua F, Wang B, Mao W, Feng XR, Li JY and Wang X: Serum microRNA $125 \mathrm{~b}$ as a diagnostic or prognostic biomarker for advanced NSCLC patients receiving cisplatin-based chemotherapy. Acta Pharmacol Sin 34: 309-313, 2013.

8. Perell K, Vincent M, Vainer B, Petersen BL, Federspiel B, Møller AK, Madsen M, Hansen NR, Friis-Hansen L, Nielsen FC and Daugaard G: Development and validation of a microRNA based diagnostic assay for primary tumor site classification of liver core biopsies. Mol Oncol 9: 68-77, 2015.

9. Xin H, Li X, Yang B, Zhang L, Han Z and Han C: Blood-based multiple-microRNA assay displays a better diagnostic performance than single-microRNA assay in the diagnosis of breast tumor. Tumour Biol 35: 12635-12643, 2014.

10. Schetter AJ, Leung SY, Sohn JJ, Zanetti KA, Bowman ED, Yanaihara N, Yuen ST, Chan TL, Kwong DL, Au GK, et al: MicroRNA expression profiles associated with prognosis and therapeutic outcome in colon adenocarcinoma. JAMA 299: 425-436, 2008

11. Lu J, Getz G, Miska EA, Alvarez-Saavedra E, Lamb J, Peck D, Sweet-Cordero A, Ebert BL, Mak RH, Ferrando AA, et al: MicroRNA expression profiles classify human cancers. Nature 435: 834-838, 2005.

12. Zhu SM, Chen CM, Jiang ZY, Yuan B, Ji M, Wu FH and Jin J: MicroRNA-185 inhibits cell proliferation and epithelial-mesenchymal transition in hepatocellular carcinoma by targeting Six2. Eur Rev Med Pharmacol Sci 20: 1712-1719, 2016.

13. Deng B, Qu L, Li J, Fang J, Yang S, Cao Z, Mei Z and Sun X: MiRNA-211 suppresses cell proliferation, migration and invasion by targeting SPARC in human hepatocellular carcinoma. Sci Rep 6: 26679, 2016.

14. Guo LM, Pu Y, Han Z, Liu T, Li YX, Liu M, Li X and Tang H: MicroRNA-9 inhibits ovarian cancer cell growth through regulation of NF-kappaB1. FEBS J 276: 5537-5546, 2009.

15. Tsai KW, Liao YL, Wu CW, Hu LY, Li SC, Chan WC, Ho MR, Lai CH, Kao HW, Fang WL, et al: Aberrant hypermethylation of miR-9 genes in gastric cancer. Epigenetics 6: 1189-1197, 2011.

16. Zhang H, Qi M, Li S, Qi T, Mei H, Huang K, Zheng L and Tong Q: microRNA-9 targets matrix metalloproteinase 14 to inhibit invasion, metastasis, and angiogenesis of neuroblastoma cells. Mol Cancer Ther 11: 1454-1466, 2012.

17. Zheng L, Qi T, Yang D, Qi M, Li D, Xiang X, Huang K and Tong Q: microRNA-9 suppresses the proliferation, invasion and metastasis of gastric cancer cells through targeting cyclin D1 and Ets1. PLoS One 8: e55719, 2013.

18. Muraoka T, Soh J, Toyooka S, Maki Y, Shien K, Furukawa M, Ueno T, Tanaka N, Yamamoto H, Asano H, et al: Impact of aberrant methylation of microRNA-9 family members on non-small cell lung cancers. Mol Clin Oncol 1: 185-189, 2013.

19. Wang J, Zhao H, Tang D, Wu J, Yao G and Zhang Q: Overexpressions of microRNA-9 and microRNA-200c in human breast cancers are associated with lymph node metastasis. Cancer Biother Radiopharm 28: 283-288, 2013.

20. $\mathrm{Wu} \mathrm{S}$, Jia S and Xu P: MicroRNA-9 as a novel prognostic biomarker in human laryngeal squamous cell carcinoma. Int J Clin Exp Med 7: 5523-5528, 2014.

21. Zhou X, Marian C, Makambi KH, Kosti O, Kallakury BV, Loffredo CA and Zheng YL: MicroRNA-9 as potential biomarker for breast cancer local recurrence and tumor estrogen receptor status. PLoS One 7: e39011, 2012.

22. Zhu L, Chen H, Zhou D, Li D, Bai R, Zheng S and Ge W: MicroRNA-9 up-regulation is involved in colorectal cancer metastasis via promoting cell motility. Med Oncol 29: 1037-1043, 2012.

23. Sun J, Fang K, Shen H and Qian Y: MicroRNA-9 is a ponderable index for the prognosis of human hepatocellular carcinoma. Int $\mathrm{J}$ Clin Exp Med 8: 17748-17756, 2015.

24. Clement PM, Johansson HE, Wolff EC and Park MH: Differential expression of eIF5A-1 and eIF5A-2 in human cancer cells. FEBS J 273: 1102-1114, 2006.

25. Lee NP, Tsang FH, Shek FH, Mao M, Dai H, Zhang C, Dong S, Guan XY, Poon RT and Luk JM: Prognostic significance and therapeutic potential of eukaryotic translation initiation factor 5A (eIF5A) in hepatocellular carcinoma. Int J Cancer 127: 968-976, 2010. 
26. Yang GF, Xie D, Liu JH, Luo JH, Li LJ, Hua WF, Wu HM, Kung HF, Zeng YX and Guan X: Expression and amplification of eIF-5A2 in human epithelial ovarian tumors and overexpression of EIF-5A2 is a new in dependent predictor of outcome in patients with ovarian carcinoma. Gynecol Oncol 112: 314-318, 2009.

27. Luo JH, Hua WF, Rao HL, Liao YJ, Kung HF, Zeng YX, Guan XY, Chen W and Xie D: Overexpression of EIF-5A2 predict s tumor recurrence and progression in $\mathrm{pTa} / \mathrm{pT} 1$ urothelial carcinoma of the bladder. Cancer Sci 100: 896-902, 2009.

28. He LR, Zhao HY, Li BK, Liu YH, Liu MZ, Guan XY, Bian XW, Zeng YX and Xie D: Overexpression of eIF5A-2 is an adverse prognostic marker of survival in stage I non-small cell lung cancer patients. Int J Cancer 129: 143-150, 2011.

29. Tang DJ, Dong SS, Ma NF, Xie D, Chen L, Fu L, Lau SH, Li Y, Li Y and Guan XY: Overexpression of eukaryotic initiation factor $5 \mathrm{~A} 2$ enhances cell motility and promotes tumor metastasis in hepatocellular carcinoma. Hepatology 51: 1255-1263, 2010.

30. Zhu W, Cai MY, Tong ZT, Dong SS, Mai SJ, Liao YJ, Bian XW, Lin MC, Kung HF, Zeng YX, et al: Overexpression of EIF5A2 promotes colorectal carcinoma cell aggressiveness by upregulating MTA1 through C-myc to induce epithelial-mesenchymaltransition. Gut 61: 562-575, 2012.

31. Livak KJ and Schmittgen TD: Analysis of relative gene expression data using real-time quantitative PCR and the 2(-Delta Delta C(T)) method. Methods 25: 402-408, 2001.

32. He L and Hannon GJ: MicroRNAs: Small RNAs with a big role in gene regulation. Nat Rev Genet 5: 522-531, 2004.

33. Sun Z, Han Q, Zhou N, Wang S, Lu S, Bai C and Zhao RC: MicroRNA-9 enhances migration and invasion through KLF17 in hepatocellular carcinoma. Mol Oncol 7: 884-894, 2013.

34. Ye M, Du YL, Nie YQ,Zhou ZW, Cao J and Li YF: Overexpression of activated leukocute cell adhesion molecule in gastric cancer is associated with advanced stages and poor prognosis and miR-9 deregulation. Mol Med Rep 11: 2004-2012, 2015.

35. Xie D, Ma NF, Pan ZZ, Wu HX, Liu YD, Wu GQ, Kung HF and Guan XY: Overexpression of EIF-5A2 is associated with metastasis of human colorectal carcinoma. Hum Pathol 39: 80-86, 2008

36. Shek FH, Fatima $S$ and Lee NP: Implications of the use of eukaryotic translation initiation factor 5A (eIF5A) for prognosis and treatment of hepatocellular carcinoma. Int J Hepatol 2012: $760928,2012$.

37. Wei JH, Cao JZ, Zhang D, Liao B, Zhong WM, Lu J, Zhao HW, Zhang JX, Tong ZT, Fan S, et al: EIF5A2 predicts outcome in localised invasive bladder cancer and promotes bladder cancer cell aggressiveness in vitro and in vivo. Br J Cancer 110: $1767-1777,2014$
38. Lou B, Fan J, Wang K, Chen W, Zhou X, Zhang J, Lin S, Lv F and Chen Y: N1-guanyl-1,7-diaminoheptane (GC7) enhances the therapeutic efficacy of doxorubicin by inhibiting activation of eukaryotic translation initiation factor 5A2 (eIF5A2) and preventing the epithelial-mesenchymal transition in hepatocellular carcinoma cells. Exp Cell Res 319: 2708-2717, 2013.

39. Liu RR, Lv YS, Tang YX, Wang YF, Chen XL, Zheng XX, Xie SZ, Cai Y, Yu J and Zhang XN: Eukaryotic translation initiation factor $5 \mathrm{~A} 2$ regulates the migration and invasion of hepatocellular carcinoma cells via pathways involving reactive oxygen species. Oncotarget 7: 24348-24360, 2016.

40. Iida M, Brand TM, Starr MM, Huppert EJ, Luthar N, Bahrar H, Coan JP, Pearson HE, Salgia R and Wheeler DL: Overcoming acquired resistance to cetuximab by dual targeting HER family receptors with antibody-based therapy. Mol Cancer 13: 242, 2014

41. Bonner JA, Harari PM, Giralt J, Azarnia N, Shin DM, Cohen RB, Jones CU, Sur R, Raben D, Jassem J, et al: Radiotherapy plus cetuximab for squamous-cell carcinoma of the head and neck. N Engl J Med 354: 567-578, 2006.

42. Cuninham D, Humblet Y, Siena S, Khayat D, Bleiberg H, Santoro A, Best D, Mueser M, Harstrick A, Verslype C, et al: Cetuximab monotherapy and cetuximab plus irinotecan in irinotecan-refractory metastatic colorectal cancer. N Engl J Med 351: 337-345, 2004.

43. Wang $X$, Jiang R, Cui EH, Feng WM, Guo HH, Gu DH, Tang CW, Xue T and Bao Y: N1-guanyl-1,7-diaminoheptane enhances the chemosensitivity of NSCLC cells to cetuximab through inhibition of eukaryotic translation initiation factor 5A2 activation. Eur Rev Med Pharmacol Sci 20: 1244-1250, 2016.

44. Ezzoukhry Z, Louandre C, Trécherel E, Godin C, Chauffert B, Dupont S, Diouf M, Barbare JC, Maziere JC and Galmiche A: EGFR activation is a potential determinant of primary resistance of hepatocellular carcinoma cells to sorafenib. Int J Cancer 131: 2961-2969, 2012

45. Chen W, Shen X, Xia X, Xu G, Ma T, Bai X and Liang T: NSC 74859-mediated inhibition of STAT3 enhances the anti-proliferative activity of cetuximab in hepatocellular carcinoma. Liver Int 32: 70-77, 2012.

This work is licensed under a Creative Commons Attribution-NonCommercial-NoDerivatives 4.0 International (CC BY-NC-ND 4.0) License. 